Article

\title{
A Novel Strategy for Sensorless Control of IPMSM with Error Compensation Based on Rotating High Frequency Carrier Signal Injection
}

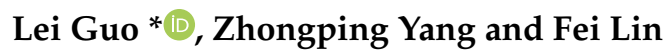 \\ School of Electrical Engineering, Beijing Jiaotong University, No. 3 Shangyuancun, Beijing 100044, China; \\ zhpyang@bjtu.edu.cn (Z.Y.); flin@bjtu.edu.cn (F.L.) \\ * Correspondence: Leitdg@bjtu.edu.cn; Tel.: +86-1360-102-2686
}

Received: 22 November 2019; Accepted: 13 April 2020; Published: 14 April 2020

\begin{abstract}
In the applications of rail transit and electric vehicles, sensorless control of interior permanent magnet synchronous motor (IPMSM) usually uses high frequency (HF) signal injection in low speed or zero speed. Rotating HF signal injection based on the stationary reference frame can identify the rotor position, but its accuracy is easily affected by various nonlinearities of the control system and stator resistance. In this paper, the causes of rotor position estimation deviation are analyzed and deduced in detail. It is proposed that the rotor position estimation deviation can be divided into high frequency phase deviation (HFPD) and stator resistance phase deviation. On the basis of these analyses, a novel sensorless rotor position estimation strategy for IPMSM is proposed. This strategy can theoretically eliminate the HF phase deviation caused by the nonlinearity of the control system and reduce the phase deviation caused by the stator resistance. Although the factors that cause the estimation deviation of rotor position may change with the time and the operation status of the motor, the proposed strategy has the characteristics of online calculation and real-time compensation, which can improve the accuracy of the estimated rotor position. In addition, this paper provides a detailed theoretical derivation of resolving rotor position considering stator resistance and HF phase deviation. Finally, the result analysis on an IPMSM demonstrate the correctness of the theoretical analysis and the effectiveness of the strategy.
\end{abstract}

Keywords: electric vehicles; interior permanent magnet synchronous motor (IPMSM); rotating high frequency (HF) signal injection; high frequency phase deviation (HFPD); rotor position estimation

\section{Introduction}

Permanent magnet synchronous motors (PMSM) are widely used in transportation, industrial automation, artificial intelligence and aerospace due to their high torque density, power density and efficiency. In order to achieve high-performance motor control using the field-oriented method, it is necessary to accurately obtain the rotor position and phase current of the motor. If the rotor position detection is inaccurate, delayed or advanced, it will inevitably reduce the stability, smoothness, accuracy and dynamics of the motor control, and even prevent the motor from starting normally. Therefore, accurate detection of rotor position becomes a key technology for permanent magnet synchronous motor control. The rotor position is usually obtained with a high precision mechanical sensor. However, these sensors introduce disadvantages, such as additional machine dimensions, higher cost, low reliability and anti-interference. Accordingly, much research has been conducted on the sensorless control of a permanent magnet synchronous motor [1-14].

The control methods of sensorless PMSM can be generally divided into two categories: the control method based on the back electromotive force (EMF) and the control method of high frequency (HF) 
signal injection $[3,5]$. According to the type of injected carrier signal, HF signal injection methods can be further classified into a HF rotating carrier signal injection method and HF pulsating carrier signal injection method [8-15].

The HF pulse signal injection method is to inject the carrier signal into the rotating reference frame. The envelope curve amplitude of the HF response current contains the rotor position information. Signal processing is essentially the demodulation of the amplitude of the HF response current. The HF pulsating signal injection method has these disadvantages, such as long convergence time, sensitivity to parameters, and even motor start failure. The HF rotating signal injection method is to inject the carrier signal into the stationary reference frame. The HF response current phase contains the rotor position information of the interior permanent magnet synchronous motor (IPMSM). Therefore, the signal processing is essentially the demodulation of the high frequency response current phase [9-28].

In comparison, the HF rotating signal injection method in stationary reference frame is insensitive to parameters, good stability, easy to converge and easy to implement in engineering. Therefore, it is widely used in the sensorless rotor position estimation of IPMSM in low speed and standstill. However, the rotor position estimation based on a high frequency rotating signal injection method is easily affected by stator resistance, the nonlinearity of converter and spatial field [7,8], and system delays, including current sensor, semiconductors switches and A/D converters, so compensation is necessary to improve the accuracy of rotor position estimation $[9,18-25]$.

In the rotating coordinate system, the effects of nonlinearity and stator resistance on the rotor estimated position error are analyzed. A small, uncompensated delay angle will lead to a large error angle in estimated rotor position in [13]. An analytical model is derived that reveals the intrinsic properties of the zero clamp effect of HF carrier signal injection. An online compensation strategy is proposed to compensate the harmful disturbance voltage due to the zero current clamping effect in [15]. The nonlinear behavior of the inverter plays the most important role in the injected carrier voltage distortion [18-24]. The influence of inverter nonlinearity on high frequency carrier injected voltage is described, and the causes are explained in detail in [21]. The nonlinear influence of inverter can be regarded as the interference source of voltage. The undesired response current caused by the disturbance voltage can distort the carrier signal resulting currents and increases estimated rotor position errors. The effects of dead time and parasitic capacitance of the converter based on HF signal injection on rotor position estimation are discussed. Actually, the position-independent positive sequence carrier current distortion caused by the nonlinear effects of the converter helps to compensate for the effect of the nonlinearity of the inverter on the position estimate in [22].

In [23], in order to reduce the nonlinear influence of the voltage converter, it is proposed to replace the voltage source inverter with the linear characteristics of the matrix converter. However, the paper only discusses the operation of the matrix converter in the low speed and zero speed regions of the motor, and requires additional harmonics to reduce the effects of nonlinear harmonics. In [24], two HF rotating carrier voltage signals with different rotation frequencies and directions are simultaneously injected into a stationary coordinate system. By demodulating the high frequency response current and establishing equations, the rotor position estimation can be calculated directly. This method is complicated and also ignores the influence of HF injection signals each other and the influence of HF signals on system parameters. In $[25,26]$, when the motor starts or the speed changes, the second $\mathrm{HF}$ alternating carrier different from the main carrier is injected into the motor to compensate the transient observer error. However, the effects of stator resistance, system delay and nonlinearity are not considered.

When using the sensorless HF rotating carrier signal injection method in the stationary reference frame, these factors, such as dead time and inverter nonlinearity, stator resistance and system delays consisting of sensors, device switches and A/D converters, will cause phase error of rotor position and result in inaccurate estimation of rotor position. Considering these factors that cause rotor position deviation and the theoretical derivation of high frequency rotating carrier injection method, a novel control strategy of rotor position estimation with error compensation is proposed. This strategy can 
theoretically eliminate the high frequency phase deviation (HFPD) caused by the nonlinearity and delay of the control system, and reduce the rotor position error caused by the stator resistance. In this paper, comparative verification between the proposed method and the conventional method of rotor position estimation are carried out, and the static and dynamic characteristics of the proposed method are tested. Finally, the results on IPMSM verify the correctness and effectiveness of the proposed error compensation strategy.

\section{Conventional Rotating HF Signal Injection Method}

The basic model of the IPMSM is described as (1) in the rotating $d q$-reference frame and the $d$-axis aligns with the direction of the rotor flux [9]. If the cross-coupled and multi-saliency of the machine are negligible, the IPMSM flux equation can be expressed as shown in (2)

$$
\begin{gathered}
{\left[\begin{array}{l}
u_{d} \\
u_{q}
\end{array}\right]=\left[\begin{array}{cc}
R_{s} & 0 \\
0 & R_{s}
\end{array}\right]\left[\begin{array}{l}
i_{d} \\
i_{q}
\end{array}\right]+\left[\begin{array}{cc}
p & -\omega_{r} \\
\omega_{r} & p
\end{array}\right]\left[\begin{array}{l}
\psi_{d} \\
\psi_{q}
\end{array}\right]} \\
{\left[\begin{array}{l}
\psi_{d} \\
\psi_{q}
\end{array}\right]=\left[\begin{array}{cc}
L_{\sigma d} & 0 \\
0 & L_{\sigma d}
\end{array}\right]\left[\begin{array}{l}
i_{d} \\
i_{q}
\end{array}\right]+\left[\begin{array}{c}
\psi_{f} \\
0
\end{array}\right]}
\end{gathered}
$$

where $L_{\sigma d}, L_{\sigma q}, u_{d}, u_{q}, i_{d}, i_{q}, R_{s}, \omega_{r}, \psi_{d}, \psi_{q}, \psi_{f}$ and $p$ are $d q$-axis inductance, $d q$-axis voltage, $d q$-axis current, stator resistance, motor electrical speed, $d$-axis flux linkage, $q$-axis flux linkage, flux linkage of the rotor and the derivative operator, respectively. The estimated angle is $\hat{\theta}$ and the actual angle is $\theta$ in stationary reference frame, as shown in Figure 1.

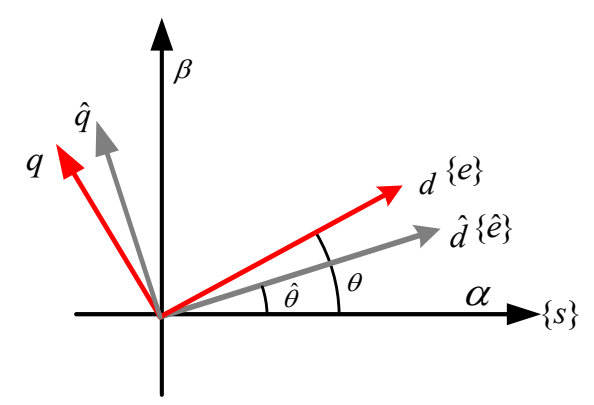

Figure 1. Actual and estimated rotor angle in stationary reference frame.

When the motor is at zero speed or low speed, the EMF induced by the rate of change of magnetic flux is neglected. The frequency of the injected HF carrier signal is much higher than the fundamental frequency of the motor, so the stator resistance can be ignored. In the stationary reference frame, the high frequency signal model of IPMSM is shown as in (3).

$$
\left[\begin{array}{l}
u_{\alpha h} \\
u_{\beta h}
\end{array}\right]=T(\theta)\left[\begin{array}{cc}
L_{\sigma d} & \\
& L_{\sigma q}
\end{array}\right] T^{-1}(\theta) \cdot p\left[\begin{array}{c}
i_{\alpha h} \\
i_{\beta h}
\end{array}\right] \quad T(\theta)=\left[\begin{array}{cc}
\cos \theta & -\sin \theta \\
\sin \theta & \cos \theta
\end{array}\right]
$$

where $u_{\alpha h}, u_{\beta h}, i_{\alpha h}, i_{\beta h}$ are the voltage and current of $\alpha \beta$-axis. $T(\theta)$ is coordinate transformation matrix. The rotating high frequency carrier voltage can be described in stationary reference frame as follows:

$$
u_{c}^{\{\}}=\left[\begin{array}{l}
u_{\alpha h} \\
u_{\beta h}
\end{array}\right]=u_{c m}\left[\begin{array}{c}
\cos \left(\omega_{c} t\right) \\
\sin \left(\omega_{c} t\right)
\end{array}\right]=u_{c m} e^{j \omega_{c} t}
$$

where $u_{c m}, \omega_{c}$ represent the amplitude and frequency of the injected HF voltage, respectively. To transform the HF carrier voltage from the stationary coordinate to the rotating reference frame is multiplied by $e^{-j \theta}$ as

$$
u_{c}^{\{e\}}=u_{c}^{\{s\}} \cdot e^{-j \theta}=u_{c m} e^{j\left(\omega_{c} t-\theta\right)}
$$


When the stator resistance is ignored, the high frequency response current of IPMSM is shown as Equation (6)

$$
u_{c}^{\{e\}}=u_{c m} e^{j\left(\omega_{c} t-\theta\right)}=L_{\sigma}^{\{e\}} \frac{d i_{c}}{d t}
$$

$L_{\sigma}^{\{e\}}$ represents the stator inductance. The solution of (6) in rotating reference frame is

$$
i_{c}^{\{e\}}=\frac{u_{c m} \sin \left(\omega_{c} t-\theta\right)}{\omega_{c} L_{\sigma d}}-j \frac{u_{c m} \cos \left(\omega_{c} t-\theta\right)}{\omega_{c} L_{\sigma q}}
$$

$L_{\sigma d}, L_{\sigma q}$ are the stator inductance of $d$-axis and $q$-axis. In order to transform the carrier current back to the stationary reference frame, the Equation (7) is multiplied by $e^{j \theta}$ as follows:

$$
\begin{aligned}
i_{c}^{\{e\}} \cdot e^{j \theta} & =i_{c}^{\{s\}}=i_{c p}^{\{s\}}+i_{c n}^{\{s\}} \\
& =\frac{-j u_{c m}}{2 \omega_{c} L_{\sigma d} L_{\sigma q}}\left\{\left(L_{\sigma q}+L_{\sigma d}\right) e^{j\left(\omega_{c} t\right)}+\left(L_{\sigma d}-L_{\sigma q}\right) e^{j\left(-\omega_{c} t+2 \theta\right)}\right\}
\end{aligned}
$$

where $i_{c p}^{\{s\}}, i_{c n}^{\{s\}}$ represent the response current of positive and negative sequence components in the stationary reference frame. The first term of (8), the positive sequence component $i_{c p}^{\{s\}}$, does not contain rotor position information. The second term of (8), the negative sequence component $i_{c n}^{\{s\}}$, contains rotor position information and can be used to estimate rotor position.

Therefore, the conventional method obtains the estimated rotor position by multiplying the negative sequence component by $e^{j\left(\omega_{c} t\right)}$ and passing the low-pass filter (LPF), as shown in (9)

$$
i_{n}^{\{s\}}=\operatorname{LPF}\left\{i_{c}^{\{e\}} \cdot e^{j\left(\omega_{c} t+\theta\right)}\right\}=\operatorname{LPF}\left\{\left(i_{c n}^{\{s\}} \cdot e^{j\left(\omega_{c} t\right)}\right\}=\frac{j u_{c m}}{2 \omega_{c} L_{\sigma d} L_{\sigma q}}\left(L_{\sigma q}-L_{\sigma d}\right) e^{j(2 \theta)}\right.
$$

where the LPF represents the algorithm operator of the low pass filter.

\section{Sensorless Control Considering Stator Resistance and System Delay}

The conventional method of estimating rotor position at low speed or standstill ignores the influence of stator resistance and also ignores the phase shift of the HF carrier injection signal caused by the nonlinearity and delays of the control system. In the rotating reference frame, the HF carrier current response of the IPMSM, considering the stator resistance, is as shown in Equation (10).

$$
u_{c}^{\{e\}}=u_{c}^{\{s\}} e^{j \omega_{c} t} \cdot e^{-j \theta}=R_{s} i_{c}^{\{e\}}+L_{\sigma}^{\{e\}} \frac{d i_{c}}{d t}
$$

If the anisotropy would be only due to rotor saliency, accordingly, there will be no coupling between $d$-axis and $q$-axis as a result of the magnetic principle of the motor. In the rotating reference frame, the solution of Equation (10) is as follows:

$$
i_{c}^{\{e\}}=\frac{u_{c m}}{Z_{d}} \cos \left(\omega_{c} t-\theta\right)+j \frac{u_{c m}}{Z_{q}} \sin \left(\omega_{c} t-\theta\right)
$$

where $Z_{d}, Z_{q}$ represent the equivalent impedance in the d-axis and q-axis direction, respectively.

Considering the HFPD caused by the nonlinear factors of the control system, such as dead time of the inverter, pulse width modulation (PWM) control algorithm and sampling delays, etc., the HF response current Equation (11) in the rotating reference frame is transformed into Equation (12) as follows:

$$
i_{c}^{\{e\}}=\frac{u_{c m}}{Z_{d}} \cos \left(\omega_{c} t-\theta-\xi_{H P D}\right)+j \frac{u_{c m}}{Z_{q}} \sin \left(\omega_{c} t-\theta-\xi_{H P D}\right)
$$

where $\xi_{H P D}$ can be written as

$$
\xi_{H P D}=\omega_{c} \tau
$$


The $\omega_{c}, \tau$ represent the HF carrier signal frequency and time delay, respectively. $\xi_{H P D}$ is the HF current phase shift, which is the total system delays cause by the nonlinearity factors of the control system during the HF carrier signal transmission process. Its value can be either positive or negative. Multiplying by the rotation factor $e^{j \theta}$, the HF response current $i_{c}^{\{e\}}$ can be transformed from the rotating reference frame to the stationary reference frame, as

$$
i_{c}^{\{s\}}=i_{c}^{\{\ell\}} \cdot e^{j(\theta)}=i_{c+}^{\{s\}}+i_{c-}^{\{s\}}
$$

Substituting Equation (12) into (14) yields the equations as shown in (15) and (16)

$$
\begin{aligned}
& i_{c+}^{\{s\}}=-j \frac{u_{c m}}{2\left|Z_{d}\right|}\left(e^{j\left(\omega_{c} t-\xi_{H P D}+\lambda_{d}\right)}-e^{-j\left(\omega_{c} t-2 \theta-\xi_{H P D}+\lambda_{d}\right)}\right)=i_{c p+}^{\{s\}}+i_{c n+}^{\{s\}} \\
& i_{c-}^{\{s\}}=-j \frac{u_{c m}}{2\left|Z_{q}\right|}\left(e^{j\left(\omega_{c} t-\xi_{H P D}+\lambda_{q}\right)}+e^{-j\left(\omega_{c} t-2 \theta-\xi_{H P D}+\lambda_{q}\right)}\right)=i_{c p-}^{\{s\}}+i_{c n-}^{\{s\}}
\end{aligned}
$$

where

$$
\begin{aligned}
& \left|Z_{d}\right|=\sqrt{R_{s}^{2}+\left(\omega_{c} L_{\sigma d}\right)^{2}}, \lambda_{d}=\tan ^{-1}\left(\frac{R_{s}}{\omega_{c} L_{\sigma d}}\right) \\
& \left|Z_{q}\right|=\sqrt{R_{s}^{2}+\left(\omega_{c} L_{\sigma q}\right)^{2}}, \lambda_{q}=\tan ^{-1}\left(\frac{R_{s}}{\omega_{c} L_{\sigma q}}\right)
\end{aligned}
$$

The HF rotation signal is contained in Equations (15) and (16), which is disadvantageous for obtaining the rotor position information of the low frequency. In the stationary reference frame, in order to extract the rotor position information, Equations (15) and (16) are multiplied by the HF rotation factor $e^{j \omega_{c} t}, e^{-j \omega_{c} t}$, respectively. Then the signals are passed through the low-pass filter to obtain the negative sequence current component containing the rotor position information and the positive sequence current component, as shown in (18) and (19).

$$
\begin{aligned}
i_{c p}^{\{s\}\left(-\omega_{c} t\right)}= & \operatorname{LPF}\left\{\left(i_{c p+}^{\{s\}}+i_{c n+}^{\{s\}}\right) e^{-j \omega_{c} t}+\left(i_{c p-}^{\{s\}}+i_{c n-}^{\{s\}}\right) e^{-j \omega_{c} t}\right\}=\operatorname{LPF}\left(i_{c p+}^{\{s\}} \cdot e^{-j \omega_{c} t}+i_{c p-}^{\{s\}} \cdot e^{-j \omega_{c} t}\right) \\
= & \operatorname{LPF}\left(i_{c p}^{\{s\}} \cdot e^{-j \omega_{c} t}\right)=-j \frac{u_{c m}}{2}\left(\frac{e^{j\left(\lambda_{d}-\xi_{H P D}\right)}}{\left|Z_{d}\right|}+\frac{e^{j\left(\lambda_{q}-\xi_{H P D}\right)}}{\left|Z_{q}\right|}\right) \\
i_{c n}^{\{s\}\left(\omega_{c} t\right)} & =\operatorname{LPF}\left\{\left(i_{c p+}^{\{s\}}+i_{c n+}^{\{s\}}\right) e^{j \omega_{c} t}+\left(i_{c p-}^{\{s\}}+i_{c n-}^{\{s\}}\right) e^{j \omega_{c} t}\right\}=\operatorname{LPF}\left(i_{c n+}^{\{s\}} \cdot e^{j \omega_{c} t}+i_{c n-}^{\{s\}} \cdot e^{j \omega_{c} t}\right) \\
& =\operatorname{LPF}\left(i_{c n}^{\{s\}} \cdot e^{j \omega_{c} t}\right)=j \frac{u_{c m}}{2}\left(\frac{e^{j\left(2 \theta-\lambda_{d}+\xi_{H P D}\right)}}{\left|Z_{d}\right|}-\frac{e^{j\left(2 \theta-\lambda_{q}+\xi_{H P D}\right)}}{\left|Z_{q}\right|}\right)
\end{aligned}
$$

From the positive and negative sequence components of (18) and (19), it can be seen that various factors can cause errors in rotor position identification. In order to analyze the influence of various factors on the rotor position, (18) and (19) can be further simplified as shown in (20) and (21)

$$
\begin{gathered}
i_{c p}^{\{s\}\left(-\omega_{c} t\right)}=-j \frac{u_{c m}}{2}\left(\frac{e^{j\left(\lambda_{d}-\xi_{H P D}\right)}}{\left|Z_{d}\right|}+\frac{e^{j\left(\lambda_{q}-\xi_{H P D}\right)}}{\left|Z_{q}\right|}\right)=(X+j Y)=K_{c p} e^{j \varphi_{c p}\left(\lambda_{d}, \lambda_{q}, \xi_{H P D}\right)} \\
i_{c n}^{\{s\}\left(\omega_{c} t\right)}=j \frac{u_{c m}}{2}\left(\frac{e^{j\left(-\lambda_{d}+\xi_{H P D}\right)}}{\left|Z_{d}\right|}-\frac{e^{j\left(-\lambda_{q}+\xi_{H P D}\right)}}{\left|Z_{q}\right|}\right) e^{j(2 \theta)}=(Z+j W) e^{j(2 \theta)}=K_{c n} e^{j\left\{\varphi_{c n}\left(\lambda_{d}, \lambda_{q}, \xi_{H P D}\right)+2 \theta\right\}}
\end{gathered}
$$

where

$$
\begin{aligned}
& X=\operatorname{Re}\left\{-j \frac{u_{c m}}{2}\left(\frac{e^{j\left(\lambda_{d}-\xi_{H P D}\right)}}{\left|Z_{d}\right|}+\frac{e^{j\left(\lambda_{q}-\xi_{H P D}\right)}}{\left|Z_{q}\right|}\right)\right\} \\
& Y=\operatorname{Im}\left\{-j \frac{u_{c m}}{2}\left(\frac{e^{j\left(\lambda_{d}-\xi_{H P D}\right)}}{\left|Z_{d}\right|}+\frac{e^{j\left(\lambda_{q}-\xi_{H P D}\right)}}{\left|Z_{q}\right|}\right)\right\} \\
& Z=\operatorname{Re}\left\{j \frac{u_{c m}}{2}\left(\frac{e^{j\left(-\lambda_{d}+\xi_{H P D}\right)}}{\left|Z_{d}\right|}-\frac{e^{j\left(-\lambda_{q}+\xi_{H P D}\right)}}{\left|Z_{q}\right|}\right)\right\} \\
& W=\operatorname{Im}\left\{j \frac{u_{c m}}{2}\left(\frac{e^{j\left(-\lambda_{d}+\xi_{H P D}\right)}}{\left|Z_{d}\right|}-\frac{e^{j\left(-\lambda_{q}+\xi_{H P D}\right)}}{\left|Z_{q}\right|}\right)\right\}
\end{aligned}
$$


and

$$
\begin{gathered}
K_{c p}=\sqrt{X^{2}+Y^{2}}=F_{c p}\left(\omega_{c}, L_{\sigma d}, L_{\sigma q}, R_{s}, u_{c m}\right) \\
K_{c n}=\sqrt{Z^{2}+W^{2}}=F_{c n}\left(\omega_{c}, L_{\sigma d}, L_{\sigma q}, R_{s}, u_{c m}\right) \\
\varphi_{c p}\left(\lambda_{d}, \lambda_{q}, \xi_{H P D}\right)=\operatorname{Arg}\left(i_{c p}^{\{s\}\left(-\omega_{c} t\right)}\right)=\frac{\pi}{2}-\arctan \frac{X}{Y} \\
\varphi_{c n}\left(\lambda_{d}, \lambda_{q}, \xi_{H P D}\right)=\operatorname{Arg}\left(i_{c n}^{\{s\}\left(\omega_{c} t\right)}\right)=\frac{\pi}{2}-\arctan \frac{Z}{W}
\end{gathered}
$$

$\varphi_{c p}, \varphi_{c n}$ represent the rotation angle of the positive and negative sequence components. $\operatorname{Arg}()$ represents the operation of the vector angle. Through theoretical analysis and formula derivation, it can be concluded that the negative sequence component contains not only rotor position angle, but also the phase angle of stator resistance and HF phase deviation angle $\xi_{H P D}$. The positive sequence current component does not contain rotor position information, but contains HF phase deviation angle $\xi_{H P D}$ and the phase angle of stator resistance.

\subsection{Effect of Stator Resistance}

Analyzing the influence of the stator resistance on the rotor position estimation, the system nonlinear influence is ignored, that is, the HF phase deviation is assumed to be zero. Moreover, (20) and (21) can be further simplified as

$$
\begin{gathered}
i_{c p r}^{\{s\}\left(-\omega_{c} t\right)}=-j \frac{u_{c m}}{2}\left(\frac{e^{j\left(\lambda_{d}\right)}}{\left|Z_{d}\right|}+\frac{e^{j\left(\lambda_{q}\right)}}{\left|Z_{q}\right|}\right)=\left(X_{r}+j Y_{r}\right) \\
i_{c n r}^{\{s\}\left(\omega_{c} t\right)}=j \frac{u_{c m}}{2}\left[\frac{e^{j\left(-\lambda_{d}\right)}}{\left|Z_{d}\right|}-\frac{e^{j\left(-\lambda_{q}\right)}}{\left|Z_{q}\right|}\right] e^{j(2 \theta)}=\left(Z_{r}+j W_{r}\right) e^{j(2 \theta)}
\end{gathered}
$$

where $i_{c p r}^{\{s\}\left(-\omega_{c} t\right)}$ and $i_{c n r}^{\{s\}\left(\omega_{c} t\right)}$, respectively, represent the positive and negative sequence components only considering the stator resistance in the stationary reference frame. The real and imaginary parts of the positive and negative sequence components can be expressed as follows:

$$
\begin{aligned}
& X_{r}=\operatorname{Re}\left\{-j \frac{u_{c m}}{2}\left(\frac{e^{j\left(\lambda_{d}\right)}}{\left|Z_{d}\right|}+\frac{e^{j\left(\lambda_{q}\right)}}{\left|Z_{q}\right|}\right)\right\}=\frac{u_{c m} R_{s}}{2}\left(\frac{1}{\left|Z_{d}\right|^{2}}+\frac{1}{\left|Z_{q}\right|^{2}}\right) \\
& Y_{r}=\operatorname{Im}\left\{-j \frac{u_{c m}}{2}\left(\frac{e^{j\left(\lambda_{d}\right)}}{\left|Z_{d}\right|}+\frac{e^{j\left(\lambda_{q}\right)}}{\left|Z_{q}\right|}\right)\right\}=\frac{-u_{c m} \omega_{c}}{2}\left(\frac{L_{\sigma d}}{\left|Z_{d}\right|^{2}}+\frac{L_{\sigma q}}{\left|Z_{q}\right|^{2}}\right) \\
& Z_{r}=\operatorname{Re}\left\{j \frac{u_{c m}}{2}\left(\frac{e^{j\left(-\lambda_{d}\right)}}{\left|Z_{d}\right|}-\frac{e^{j\left(-\lambda_{q}\right)}}{\left|Z_{q}\right|}\right)\right\}=\frac{u_{c m} R_{s}}{2}\left(\frac{1}{\left|Z_{d}\right|^{2}}-\frac{1}{\left|Z_{q}\right|^{2}}\right) \\
& W_{r}=\operatorname{Im}\left\{j \frac{u_{c m}}{2}\left(\frac{u^{j\left(-\lambda_{d}\right)}}{\left|Z_{d}\right|}-\frac{e^{j\left(-\lambda_{q}\right)}}{\left|Z_{q}\right|}\right)\right\}=\frac{u_{c m} \omega_{c}}{2}\left(\frac{L_{\sigma d}}{\left|Z_{d}\right|^{2}}-\frac{L_{\sigma q}}{\left|Z_{q}\right|^{2}}\right)
\end{aligned}
$$

By analyzing (26) and (27), it can be found that only the imaginary part of the positive sequence component is negative value, and the others are positive values. From this, the phase impedance angle of the positive and negative sequence components can be determined. Moreover, (26) and (27) can be further simplified as shown in (29) and (30).

$$
\begin{gathered}
i_{c p r}^{\{s\}\left(-\omega_{c} t\right)}=\left(X_{r}+j Y_{r}\right)=\left|X_{r}+j Y_{r}\right| e^{j\left(-\frac{\pi}{2}-\varphi_{p}\right)} \\
i_{c n r}^{\{s\}\left(\omega_{c} t\right)}=\left(Z_{r}+j W_{r}\right)=\left|Z_{r}+j W_{r}\right| e^{j\left(2 \theta+\frac{\pi}{2}-\varphi_{n}\right)}
\end{gathered}
$$

where

$$
\begin{aligned}
\left|X_{r}+j Y_{r}\right| & =\sqrt{X_{r}^{2}+Y_{r}^{2}}, \varphi_{p}=\tan ^{-1}\left(\frac{X_{r}}{Y_{r}}\right) \\
\left|Z_{r}+j W_{r}\right| & =\sqrt{Z_{r}^{2}+W_{r}^{2}}, \varphi_{n}=\tan ^{-1}\left(\frac{Z_{r}}{W_{r}}\right)
\end{aligned}
$$


Considering the positive and negative sequence vector expressions (15), (16), (29) and (30), and the quadrants in which the vectors are located, the impedance angle expressions can be derived as shown in (32) and (33).

$$
\begin{aligned}
& \varphi_{p}=\tan ^{-1} \frac{-R_{s}\left(R_{s}^{2}+\omega_{c}^{2} L_{\sigma q}{ }^{2}\right)-R_{s}\left(R_{s}^{2}+\omega_{c}{ }^{2} L_{\sigma d}{ }^{2}\right)}{\omega_{c} L_{\sigma d}\left(R_{s}^{2}+\omega_{c} L_{\sigma q}^{2}\right)+\omega_{c} L_{\sigma q}\left(R_{s}^{2}+\omega_{c}^{2} L_{\sigma d}{ }^{2}\right)} \\
& =\tan ^{-1} \frac{2 R_{s}\left(\omega_{c}{ }^{2} L_{\sigma d} L_{\sigma q}-R_{s}^{2}\right)-\left(R_{s} \omega_{c} L_{\sigma q}+R_{s} \omega_{c} L_{\sigma d}\right) \omega_{c}\left(L_{\sigma d}+L_{\sigma q}\right)}{\omega_{c}\left(L_{\sigma d}+L_{\sigma q}\right)\left(\omega_{c}{ }^{2} L_{\sigma d} L_{\sigma q}-R_{s}{ }^{2}\right)-\left(-2 R_{s}\right)\left(R_{s} \omega_{c} L_{\sigma q}+R_{s} \omega_{c} L_{\sigma d}\right)} \\
& =\lambda_{p 1}-\lambda_{d}-\lambda_{q} \\
& \varphi_{n}=\tan ^{-1} \frac{R_{s}\left(R_{s}^{2}+\omega_{c}^{2} L_{\sigma q}{ }^{2}\right)-R_{s}\left(R_{s}^{2}+\omega_{c}^{2} L_{\sigma d^{2}}{ }^{2}\right)}{\omega_{c} L_{\sigma d}\left(R_{s}^{2}+\omega_{c}^{2} L_{\sigma q}{ }^{2}\right)-\omega_{c} L_{\sigma q}\left(R_{s}{ }^{2}+\omega_{c}^{2} L_{\sigma \sigma}{ }^{2}\right)} \\
& =\tan ^{-1} \frac{R_{s}}{\omega_{c}} \frac{\left(\omega_{c}^{2} L_{\sigma q}{ }^{2}-\omega_{c}{ }^{2} L_{\sigma d}{ }^{2}\right)}{\left(L_{\sigma d} R_{s}^{2}+\omega_{c}{ }^{2} L_{\sigma d} L_{\sigma q}{ }^{2}-L_{\sigma q} R_{s}{ }^{2}-\omega_{c}^{2} L_{\sigma q} L_{\sigma d}{ }^{2}\right)} \\
& =\lambda_{d}+\lambda_{q}
\end{aligned}
$$

where

$$
\lambda_{p 1}=\tan ^{-1} \frac{2 R_{s}}{\omega_{c}\left(L_{\sigma d}+L_{\sigma q}\right)}
$$

Substituting (32), (33) and (34) into (29) and (30), we obtain

$$
\begin{aligned}
& i_{c p r}^{\{s\}\left(-\omega_{c} t\right)}=K_{c p}^{r} \cdot e^{j\left(-\frac{\pi}{2}-\lambda_{p 1}+\lambda_{d}+\lambda_{q}\right)} \\
& i_{c n r}^{\{s\}\left(\omega_{c} t\right)}=K_{c n}^{r} \cdot e^{j\left(2 \theta+\frac{\pi}{2}-\lambda_{d}-\lambda_{q}\right)}
\end{aligned}
$$

where

$$
\begin{aligned}
K_{c p}^{r} & =\sqrt{X_{r}^{2}+Y_{r}^{2}}=F_{c p}\left(\omega_{c}, L_{\sigma d}, L_{\sigma q}, R_{s}, u_{c m}\right) \\
K_{c n}^{r} & =\sqrt{Z_{r}^{2}+W_{r}^{2}}=F_{c n}\left(\omega_{c}, L_{\sigma d}, L_{\sigma q}, R_{s}, u_{c m}\right)
\end{aligned}
$$

$K_{c p}^{r}, K_{c n}^{r}$ are multivariable functions whose values are greater than zero and are related to the parameters $\omega_{c}, L_{\sigma d}, L_{\sigma q}, R_{s}, u_{c m}$.

Considering (17) and (34), as well as the salient characteristics of IPMSM, it can be proved that the inequality (38) holds, as shown

$$
\left\{\begin{array}{l}
\lambda_{q}<\lambda_{p 1}<\lambda_{d} \\
\left(-\lambda_{d}-\lambda_{q}\right)<-2 \lambda_{p 1}
\end{array}\right.
$$

From (35) and (36), the negative sequence current component contains rotor position information, while the positive sequence current component contains only the angle associated with the stator resistance and inductance. The conventional method directly uses the negative sequence current to obtain the rotor position, but this method includes the rotor position error angle caused by the stator resistance and the stator inductance, which reduces the accuracy of the rotor position estimation.

\subsection{Effect of System Delays}

Analyzing the influence of system delays on the rotor position estimated, the stator resistances is neglected, (20) and (21) can be further simplified as

$$
\begin{gathered}
i_{c p p}^{\{s\}\left(-\omega_{c} t\right)}=-j \frac{u_{c m}}{2}\left(\frac{e^{j\left(-\xi_{H P D}\right)}}{\left|Z_{d}\right|}+\frac{e^{j\left(-\xi_{H P D}\right)}}{\left|Z_{q}\right|}\right)=K_{c p}^{p} \cdot e^{j\left(-\frac{\pi}{2}-\xi_{H P D}\right)} \\
i_{c n p}^{\{s\}\left(\omega_{c} t\right)}=j \frac{u_{c m}}{2}\left(\frac{e^{j\left(2 \theta+\xi_{H P D}\right)}}{\left|Z_{d}\right|}-\frac{e^{j\left(2 \theta+\xi_{H P D}\right)}}{\left|Z_{q}\right|}\right)=K_{c n}^{p} \cdot e^{j\left(2 \theta+\xi_{H P D}+\frac{\pi}{2}\right)}
\end{gathered}
$$


with

$$
\begin{aligned}
& K_{c p}^{p}=\frac{u_{c m}}{2}\left(\frac{1}{\left|Z_{d}\right|}+\frac{1}{\left|Z_{q}\right|}\right)=F_{c p}^{p}\left(\omega_{c}, L_{\sigma d}, L_{\sigma q}, R_{s}, u_{c m}\right) \\
& K_{c n}^{p}=\frac{u_{c m}}{2}\left(\frac{1}{\left|Z_{d}\right|}-\frac{1}{\left|Z_{q}\right|}\right)=F_{c n}^{p}\left(\omega_{c}, L_{\sigma d}, L_{\sigma q}, R_{s}, u_{c m}\right)
\end{aligned}
$$

where $i_{c p p}^{\{s\}\left(-\omega_{c} t\right)}$ and $i_{c n p}^{\{s\}\left(\omega_{c} t\right)}$ respectively represent the positive and negative sequence components, only considering the influence of system delays on the estimated rotor position in the stationary reference frame. $K_{c p}^{p}, K_{c n}^{p}$ are multivariable functions whose values are greater than zero and are related to the parameters $\omega_{c}, L_{\sigma d}, L_{\sigma q}, R_{s}, u_{c m}$. From (39) and (40), the negative sequence current contains rotor position information, while the positive sequence current contains only the angle associated with system delays. The conventional method directly uses the negative sequence current to obtain the rotor position, but this method includes the error angle caused by system delays, which reduces the accuracy of the rotor position estimation.

\subsection{Proposed Estimated Rotor Position Method}

According to the above analysis, in order to accurately obtain the rotor position, it is necessary to compensate the rotor position error caused by the system nonlinearity and motor parameters. From (18), (19), (29), (30), (39) and (40), in the stationary reference coordinate system, the positive sequence component and the negative sequence component of the high frequency response current are solved as shown in (42) and (43).

$$
\begin{gathered}
i_{c p}^{\{s\}\left(-\omega_{c} t\right)}=K_{c p} \cdot e^{j \varphi_{c p}}=K_{c p} \cdot e^{j\left(-\frac{\pi}{2}-\lambda_{p 1}+\lambda_{d}+\lambda_{q}-\xi_{H P D}\right)} \\
i_{c n}^{\{s\}\left(\omega_{c} t\right)}=K_{c n} \cdot e^{j\left(2 \theta+\varphi_{c n}\right)}=K_{c n} \cdot e^{j\left(2 \theta+\frac{\pi}{2}-\lambda_{d}-\lambda_{q}+\xi_{H P D}\right)}
\end{gathered}
$$

where

$$
\begin{gathered}
K_{c p}=\frac{2 u_{c m}}{R_{s}} \sqrt{\frac{4+A^{2} \omega_{c}^{2}}{16+8\left(A^{2}+B^{2}\right) \omega_{c}^{2}+\left(A^{2}-B^{2}\right)^{2} \omega_{c}^{4}}} \\
K_{c n}=\frac{2 u_{c m}}{R_{s}} \sqrt{\frac{\omega_{c}^{2} B^{2}}{16+8\left(A^{2}+B^{2}\right) \omega_{c}^{2}+\left(A^{2}-B^{2}\right)^{2} \omega_{c}^{4}}} \\
A=\frac{L_{\sigma d}+L_{\sigma q}}{R_{S}}, B=\frac{L_{\sigma q}-L_{\sigma d}}{R_{S}}
\end{gathered}
$$

According to the negative sequence current as shown in (43), the rotor position estimation error obtained by the conventional methods is mainly composed of two parts: the phase angle error caused by the stator resistance and the phase shift error caused by the HF response current. The phase angle error of the stator resistance is negative, so the effect of the stator resistance is that the estimated rotor position always lags the actual rotor position. The magnitude and polarity of the phase shift error are determined by the operating state of the system, which is real-time changing and not suitable for off-line compensation. Using the conventional method to estimate the rotor position, the rotor position error is relatively large, and the system instability is caused by the change of the rotor position error.

Although there is no rotor position information in the positive sequence component of motor current, such as (42), it contains the phase angle of stator resistance and the phase shift error of high frequency response current. In addition, the phase angle error and phase shift error of the positive sequence component are exactly opposite to that of the negative sequence component. Therefore, this paper proposes a control strategy for estimating the rotor position, the vector product method (VPM), which is to calculate the estimated rotor position by multiplying the positive sequence component and the negative sequence component of the HF response current, as shown

$$
i_{c p}^{\{s\}\left(-\omega_{c} t\right)} \cdot i_{c n}^{\{s\}\left(\omega_{c} t\right)}=K_{c p} K_{c n} e^{j\left(2 \theta-\lambda_{p 1}\right)}
$$


According to (43), (46) and inequality (38), the rotor position error caused by stator resistance in the proposed method is less than half of that in the conventional method. The vector product method (VPM) proposed in this paper can not only theoretically eliminate the HF phase shift error caused by the nonlinearity and delay of the system, but also reduce the rotor position error caused by stator resistance by half. The implementation block diagram of the proposed sensorless control system is shown in Figure 2. Where $\lambda_{p 1}$ is the compensated stator resistance error and $\xi_{H P D}$ is the eliminated HF phase shifting error. HF rotating carrier voltage signal is injected from $\alpha \beta$ stationary coordinates and space vector PWM method is used for motor control.

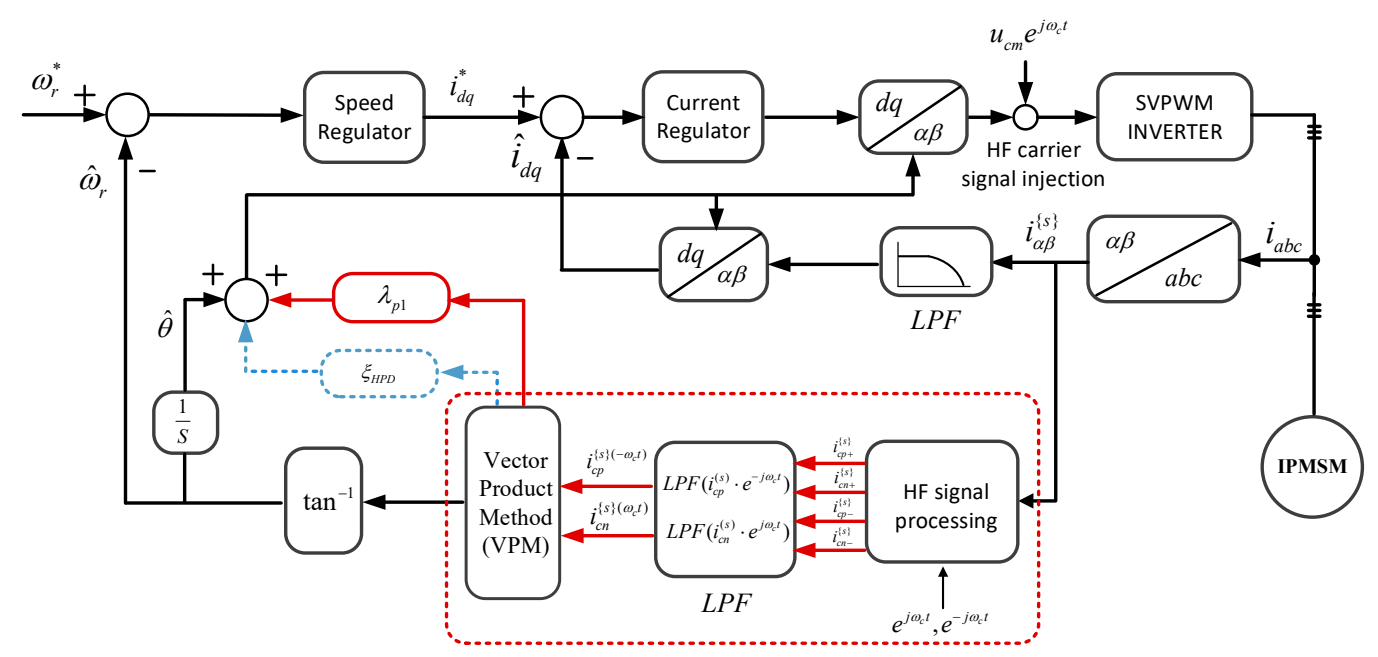

Figure 2. Block diagram of the proposed sensorless control system.

\section{Results Analysis}

In this section, in order to verify the high frequency carrier signal injection control strategy proposed in this paper, an interior permanent magnet synchronous motor simulation platform driven by voltage source inverters is built according to the laboratory IPMSM simulation experiment platform. The total block diagram of the implemented IPMSM sensorless control system is described in Figure 2.

In the sensorless control system of IPMSM, space vector pulse width modulation (SVPWM) digital control system is adopted. The actual rotor position is obtained from the permanent magnet synchronous motor and compared with the estimated rotor position obtained by the sensorless control algorithm. The change of motor torque and speed is directly given, the dead time is completed by inverter and the system delay change is realized by modifying the sampling time. The specification and main parameters of the IPMSM are listed in Table 1.

Table 1. Main parameters of IPMSM.

\begin{tabular}{cc}
\hline Parameter & IPMSM \\
\hline Rated Power & $7.5 \mathrm{~kW}$ \\
Rated speed & $1500 \mathrm{rpm}$ \\
Rated current & $15 \mathrm{~A}$ \\
Rated voltage & $380 \mathrm{~V}$ \\
Rated torque & $47 \mathrm{~N} \cdot \mathrm{m}$ \\
Phase resistance & $0.5 \Omega$ \\
d-/q-axis inductance & $5.2 \mathrm{mH} / 10.5 \mathrm{mH}$ \\
Pole number & 4 \\
\hline
\end{tabular}

The switching frequency of PWM is set to $10 \mathrm{kHz}$, and the space vector algorithm is used as the modulation strategy. The maximum allowed electrical speed $\omega \mathrm{r}$ is $3 \mathrm{~Hz}$, which is equivalent to $90 \mathrm{rpm}$ 
when the IPMSM pole numbers are 4, and the injection frequency of the HF rotating carrier signal is selected to be $1 \mathrm{kHz}$.

In order to reduce the influence of motor torque ripple, the sinusoidal injection voltage can be selected according to the DC-link voltage. The injection voltage amplitude of the HF rotating carrier signal is selected as $32 \mathrm{~V}$.

According to the theoretical analysis and deduction in this paper, the proposed VPM and conventional method can be used to calculate the estimated rotor position of HF rotating carrier signal injection. In order to compare and analyze these methods, different inverter dead time and system delay are implemented.

A comparison of the estimated rotor position waveforms when the dead time is set to 2 us and 4 us, as shown in Figure 3. As can be seen from the Figure 3, the estimated rotor position error of the conventional negative sequence component method (NSCM) is relatively large. The proposed vector product method (VPM) has a small error in rotor position estimation, and the estimated rotor position and the actual rotor position almost overlap each other. The reason of the estimated rotor position error is analyzed in the paper. Because the phase deviation caused by the stator resistance is small, the error of rotor position estimation is mainly caused by the high frequency phase deviation, caused by the nonlinearity and delay of the system.

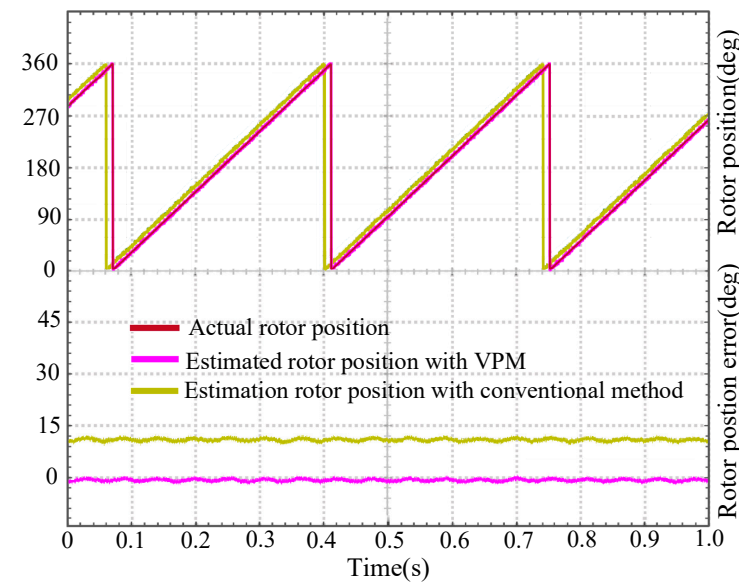

(a)

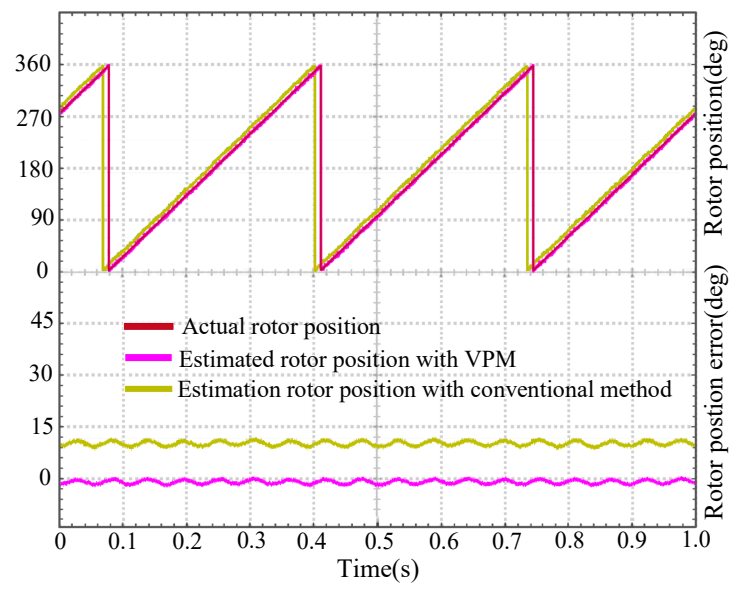

(b)

Figure 3. The estimated rotor position with different dead time using the proposed vector product method (VPM) and conventional method, respectively. (a) With dead time 2 us. (b) With dead time 4 us.

The proposed VPM method can eliminate the influence of dead time on the estimated rotor position error. The VPM method can eliminate the influence of dead time on the phase deviation of high frequency response current of estimated rotor position error.

The waveforms also shows that the variation of dead time will cause the fluctuation of rotor position. The longer the dead time, the greater the fluctuation of rotor position. This is due to the influence of low-order harmonics caused by dead time. If the dead time is too long, the system will be in an unstable state. Therefore, the dead time of inverter should be minimized to improve the accuracy of rotor position estimation. It can be seen from the Figure 3 that the proposed VPM method can also reduce the influence of harmonics to a certain extent.

Figure 4 shows the estimated rotor position comparison of the two methods when the current sampling delay is 50 us and 80 us, respectively. Changing the current sampling delay will cause a change in system delay, and the delayed sampling current was obtained through system software control. As can be seen from the Figure 4, the estimated rotor position error of the conventional method is relatively large. The proposed VPM has a small error in rotor position estimation, and 
the rotor position estimation is very close to the actual rotor position. As the delay time of sampling current becomes longer, the error of rotor position estimation by conventional method becomes larger. However, the change of rotor position error estimated by VPM method is small. The proposed VPM method can well overcome the influence of estimated rotor position error caused by sampling current delay.

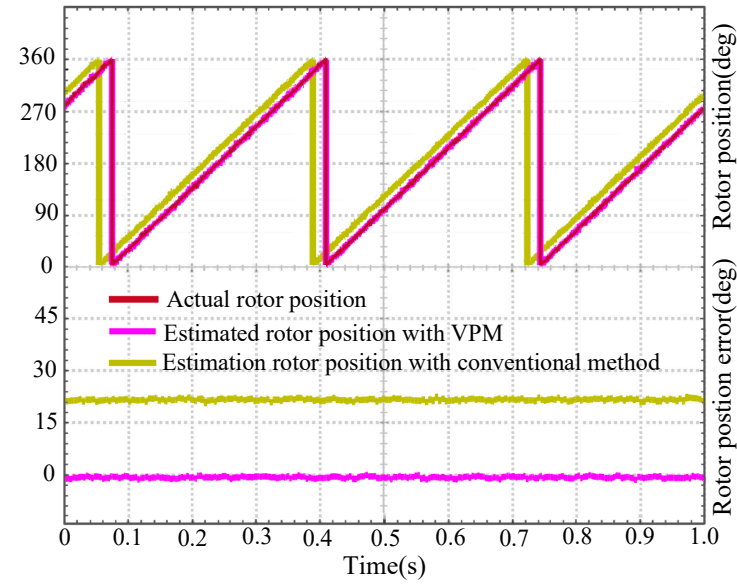

(a)

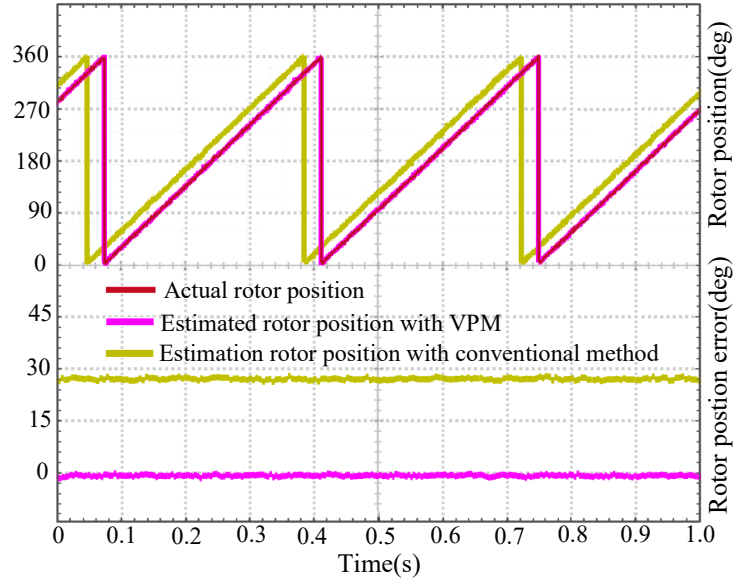

(b)

Figure 4. Rotor position estimation with different current sampling delay time using the proposed VDM and conventional method, respectively. (a) With delay time 50 us. (b) With delay time 80 us.

According to the results, (35) and (36), the proposed VPM method can theoretically eliminate the HF phase error of the system, reduce the error caused by the stator resistance, and overcome the rotor position error caused by the dead time and system delay. Therefore, the proposed method has high accuracy in rotor position estimation. The traditional negative sequence vector method has high frequency phase deviation and stator resistance deviation, so the accuracy of rotor position estimation is relatively low. The results are consistent with the theoretical conclusion, which proves the correctness and validity of the theoretical analysis.

In order to test the performance of the proposed VPM control strategy, the inverter dead time and current sampling delay was performed, as shown in Figures 5 and 6. The estimated rotor position and speed are used for the field-oriented vector control of the IPMSM. The reference speed of IPMSM is also set as $90 \mathrm{rpm}$.

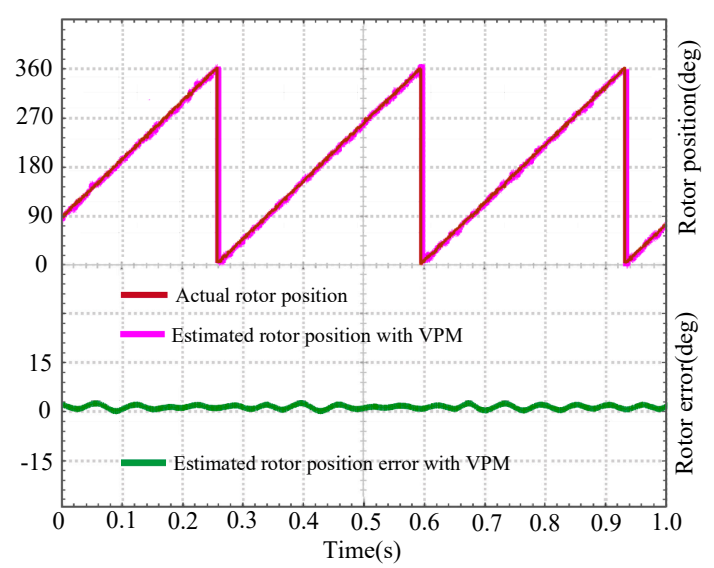

(a)

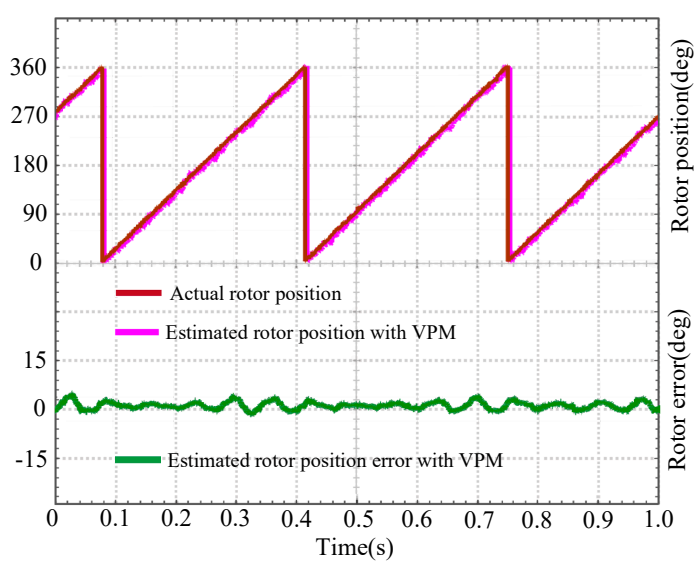

(b)

Figure 5. Estimated Rotor position with different dead time using the proposed VPM. (a) With dead time of 2 us. (b) With dead time of 4 us. 


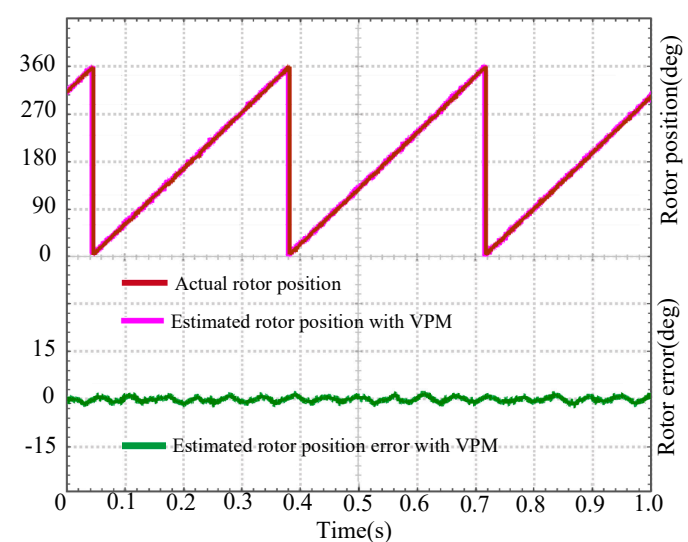

(a)

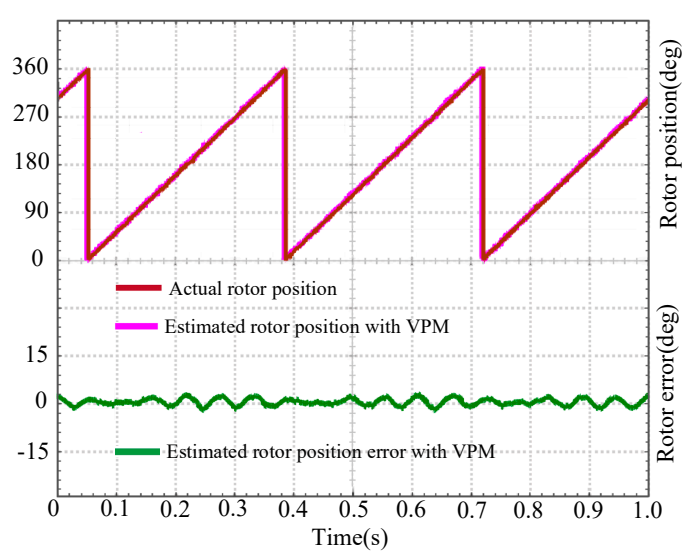

(b)

Figure 6. Rotor position estimation with different current sampling delay using the proposed VPM. (a) With sampling delay of 40 us. (b) With sampling delay of 80 us.

Figure 5 shows the results of rotor position estimation using the proposed VPM with the influence of inverter dead time. It can be seen that the error of rotor position estimation obtained by the proposed sensorless control method is relatively small, and the estimated rotor position well reflects the actual rotor position of the motor. It can be known from these results that the inverter nonlinearity does not affect the estimated rotor position obtained by the proposed VPM method.

However, with the increase of dead time, the low-order harmonics caused by the inverter increase in the fluctuation of estimated rotor position. The main cause of the rotor position fluctuation is the effect of the triple harmonics of the rotor electrical speed caused by the inverter dead time. Therefore, the dead time of the inverter should be minimized to improve the accuracy of rotor position estimation.

Figure 6 shows the curves of the estimated and actual rotor position and the rotor position error with current sampling delays set to 40 us and 80 us, respectively. Since it is difficult to measure the delay time of the circuit, the system delay is changed by changing the sampling current time on the control system.

It can be observed that the estimated rotor position error of the IPMSM is relatively small, and the estimated rotor position is close to the actual rotor position. The HF phase deviation caused by current sampling delay does not affect the estimated rotor position obtained by the proposed VPM strategy, which is consistent with the academic analysis that system delays cannot affect the rotor position estimation obtained by the proposed control strategy.

In order to test the dynamic performance of the proposed vector product method control strategy, the low-speed reverse and load changes are performed, respectively, as shown in Figures 7 and 8. In the control system, the field oriented control of the estimated rotor position and motor speed is carried out. The speed is set to $\pm 90 \mathrm{rpm}$, and the load change range is set to half load and full load. 


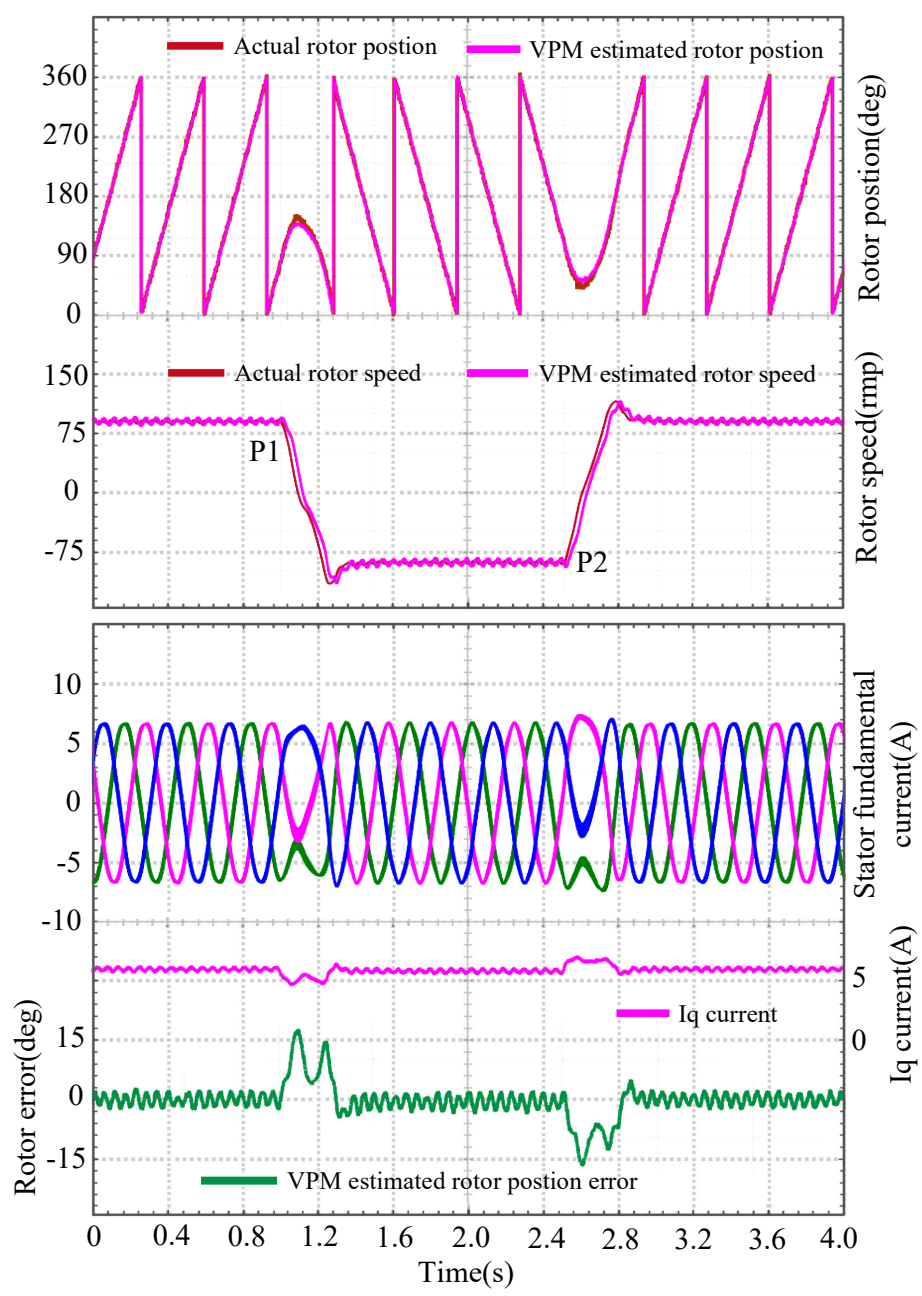

Figure 7. The results of $\pm 90 \mathrm{rpm}$ speed reverse with the proposed VPM.

The waveforms of the actual rotor speed and VPM estimated rotor speed, the actual rotor position and VPM estimated rotor position, and the VPM estimated rotor position error are presented, as shown in Figures 7 and 8 . The waveforms are obtained by the control system digital filtering and module output.

The dynamic performance test of IPMSM rotor speed change is shown in Figure 7. Before P1, the rotor speed is set to $90 \mathrm{rpm}$. At P1, the IPMSM rotor speed is set at $-90 \mathrm{rpm}$ and the motor rotor speed changes from 90 to $-90 \mathrm{rpm}$. After a few seconds, the rotor speed is again set to $90 \mathrm{rpm}$ at P2, and the rotor speed step changes from -90 to $90 \mathrm{rpm}$. It can be seen from the results that the new proposed VPM strategy has a good dynamic performance.

The dynamic performance test of IPMSM load-step change is shown in Figure 8. At P3, the load step changes from no load to half-load. The q-axis current gradually changes from $0.7 \mathrm{~A}$ to $10.5 \mathrm{~A}$ within $0.6 \mathrm{~s}$ and the rotor speed recovers to the reference speed $90 \mathrm{rpm}$ in about $0.8 \mathrm{~s}$. At P4, the load changes from a half load to a full load, and the corresponding q-axis current gradually becomes the maximum 21.2 amps in about $0.7 \mathrm{~s}$.

Although the peak value of the rotor position error only increases a little under load changes, the estimated rotor position error changes back to normal level after a short period of time. The results show that the new VPM strategy can maintain low speed under high dynamic load conditions. 

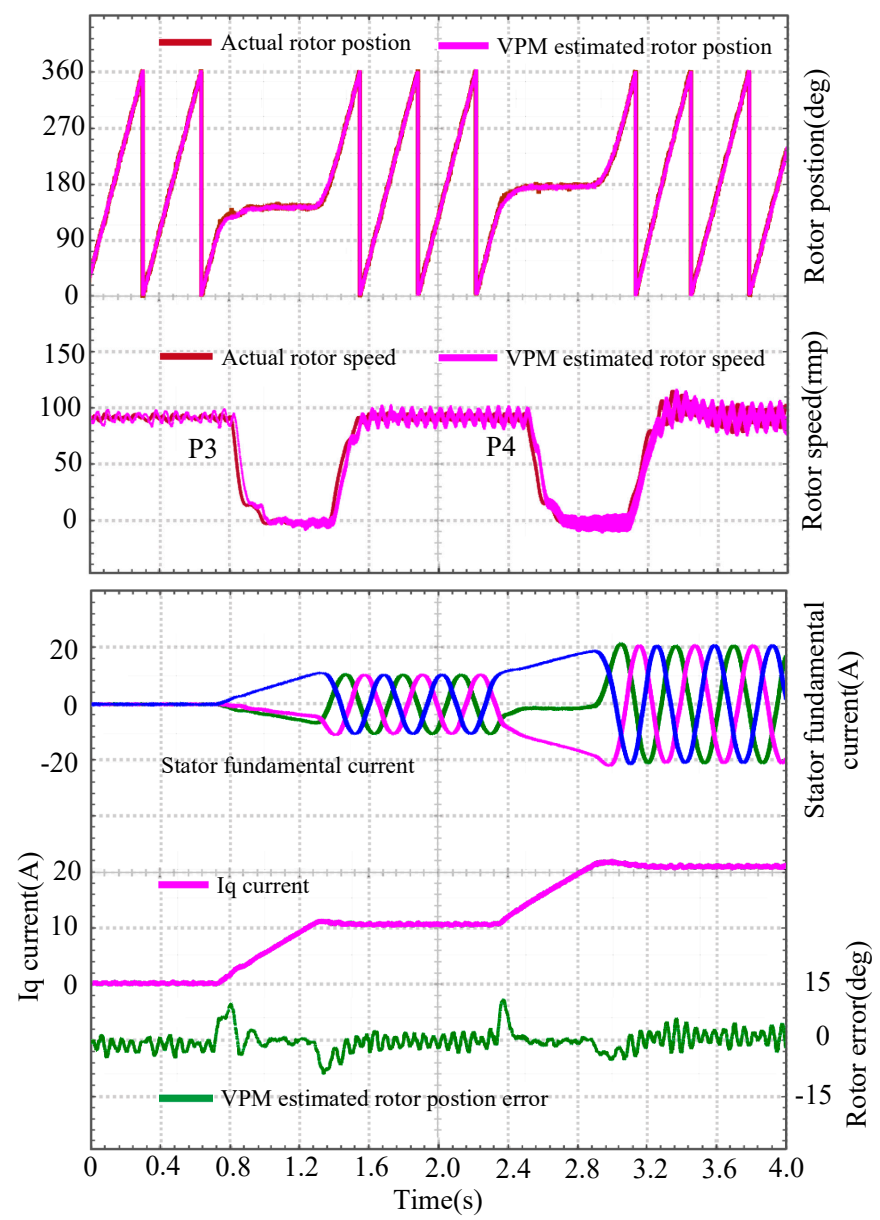

Figure 8. Waveforms of the load-step test (from no load to half load to full load) with the proposed VPM.

\section{Conclusions}

A rotating HF carrier signal injection method based on tracking rotor saliency is widely used in IPMSM sensorless control. The accuracy of rotor position obtained by the conventional method is easily affected by system delay, stator resistance and inverter nonlinearity. Considering the stator resistance and system delay, a detailed theoretical analysis and derivation of the sensorless control of the rotating HF signal injection method is presented. In this paper, the stator resistance phase deviation, high frequency phase deviation and their formation mechanism are discussed in detail, and the values of stator resistance phase deviation and high frequency phase deviation in the positive and negative sequence components are derived. Based on the theoretical analysis and derivation, a novel vector product method (VPM) sensorless control strategy is proposed. This control strategy can theoretically eliminate the high frequency phase deviation caused by the nonlinearity and delay of the control system, reduce the stator resistance phase deviation caused by the stator resistance and effectively improve the accuracy of the estimated rotor position. A comparison between the proposed VPM and the traditional negative sequence component method is carried out. The results showed that the proposed method can compensate the rotor position error with different dead times and system delays. The results verify the correctness of the theoretical analysis and the effectiveness of the error compensation strategy. Finally, the result analysis of the IPMSM demonstrate that the proposed sensorless control strategy can accurately obtain the rotor position with a good steady state and dynamic performance.

Author Contributions: Conceptualization, L.G., Z.Y. and F.L.; methodology, L.G.; software, L.G.; validation, L.G., Z.Y. and F.L.; formal analysis, L.G., Z.Y. and F.L.; investigation, F.L.; resources, L.G., Z.Y. and F.L.; data curation, L.G.; writing—original draft preparation, L.G.; writing—review and editing, Z.Y. and F.L.; visualization, L.G.; 
supervision, Z.Y. and F.L.; project administration, Z.Y.; funding acquisition, Z.Y. and F.L. All authors have read and agreed to the published version of the manuscript.

Funding: This research was funded by the Fundamental Research Funds for the Central Universities under Grant 2018YJS153.

Conflicts of Interest: The authors declare no conflict of interest.

\section{References}

1. Holtz, J. Sensorless control of induction machine-With or without signal injection. IEEE Trans. Ind. Electron. 2006, 53, 7-30. [CrossRef]

2. Chen, Z.; Doki, M.T.S.; Okuma, S. An extended electromotive force model for sensorless control of interior permanent-magnet synchronous motors. IEEE Trans. Ind. Electron. 2003, 50, 288-295. [CrossRef]

3. Nguyen, K.Q.; Nguyen, T.H.; Ha, Q.P. FPGA-based sensorless PMSM Speed control using reduced-order extended Kalman filters. IEEE Trans. Ind. Electron. 2014, 61, 6574-6582.

4. Wang, Z.; Lu, K.; Blaabjerg, F. A simple startup strategy based on current regulation for back-EMF based sensorless control of PMSM. IEEE Trans. Power Electron. 2012, 27, 3817-3825. [CrossRef]

5. Filka, R.; Asher, G.; Wheeler, P.; Silva, C. Analysis of the influence of converter non-linearities on performance of sensorless controlled synchronous PM machines algorithms. Proc. EPE 2003, 23, 34-40.

6. Ma, Z.X.; Gao, J.B.; Kennel, R. FPGA implementation of a hybrid sensorless control of SMPMSM in the whole speed range. IEEE Trans. Ind. Informat. 2013, 9, 1253-1261. [CrossRef]

7. Bernardes, T.; Montagner, V.F.; Grundling, H.A.; Pinheiro, H. Discrete-time sliding mode observer for sensorless vector control of permanent magnet synchronous machine. IEEE Trans. Ind. Electron. 2014, 61, 1679-1691. [CrossRef]

8. Wang, Q.; Zhang, G.; Wang, G.; Li, C.; Xu, D. Offline parameter self-learning method for general-purpose PMSM drives with estimation error compensation. IEEE Trans. Power Electron. 2019, 34, 11103-11115. [CrossRef]

9. Wang, G.L.; Yang, R.F.; Xu, D.G. DSP-based control of sensorless IPMSM drives for wide-speed-range operation. IEEE Trans. Ind. Electron. 2013, 60, 720-727. [CrossRef]

10. Lee, J.; Hong, J.; Nam, K.; Ortega, R.; Praly, L.; Astolfi, A. Sensorless control of surface-mount permanent-magnet synchronous motors based on a nonlinear observer. IEEE Trans. Power Electron. 2010, 25, $290-297$.

11. Bolognani, S.; Ortombina, L.; Tinazzi, F.; Zigliotto, M. Model sensitivity of fundamental-frequency based position estimators for sensorless PM and reluctance synchronous motor drives. IEEE Trans. Ind. Electron. 2018, 65, 77-85. [CrossRef]

12. Ni, R.; Xu, D.; Blaabjerg, F.; Lu, K.; Wang, G.; Zhang, G. Square-wave voltage injection algorithm for PMSM position sensorless control with high robustness to voltage errors. IEEE Trans. Power Electron. 2017, 32, 5425-5437. [CrossRef]

13. Moghadam, M.A.G.; Tahami, F. Sensorless control of PMSMs with tolerance for delays and stator resistance uncertainties. IEEE Trans. Power Electron. 2013, 28, 1391-1399. [CrossRef]

14. Wang, G.L.; Zhan, H.L.; Zhang, G.Q.; Gui, X.G.; Xu, D.G. Adaptive compensation method of position estimation harmonic error for EMF-based observer in sensorless IPMSM driver. IEEE Trans. Power Electron. 2013, 29, 3055-3064. [CrossRef]

15. Choi, C.H.; Seok, J.K. Compensation of zero-current clamping effects in high-frequency-signal-injection-based sensorless PM motor drives. IEEE Trans. Ind. Appl. 2007, 43, 1258-1265. [CrossRef]

16. Foo, G.H.B.; Rahman, M.F. Direct torque control of an IPM synchronous motor drive at very low speed using a sliding-mode stator flux observer. IEEE Trans. Power Electron. 2010, 25, 933-942. [CrossRef]

17. Yang, S.C.; Hsu, Y.L. Full speed region sensorless drive of permanentmagnet machine combining saliency-based and back-EMF-based drive. IEEE Trans. Ind. Electron. 2017, 64, 1092-1101. [CrossRef]

18. Wangetal, G. Self-commissioning of permanent magnet synchronous machine drives at standstill considering inverter nonlinearities. IEEE Trans. Power Electron. 2014, 29, 6615-6627.

19. Raca, D.; Harke, M.C.; Lorenz, R.D. Robust magnet polarity estimation for initialization of PM synchronous machines with near-zero saliency. IEEE Trans. Ind. Appl. 2008, 44, 1199-1209. [CrossRef] 
20. Kim, S.I.; Im, J.H.; Song, E.Y.; Kim, R.Y. A new rotor position estimation method of IPMSM using all-pass filter on high-frequency rotating voltage signal injection. IEEE Trans. Ind. Electron. 2016, 63, 6499-6509. [CrossRef]

21. Guerrero, J.M.; Leetmaa, M.; Briz, F.; Zamarron, A.; Lorenz, R.D. Inverter nonlinearity effects in high-frequency signal-injection-based sensorless control methods. IEEE Trans. Ind. Appl. 2005, 41, 618-626. [CrossRef]

22. Gong, L.M.; Zhu, Z.Q. A novel method for compensating inverter nonlinearity effects in carrier signal injection-based sensorless control from positive-sequence carrier current distortion. IEEE Trans. Ind. Appl. 2011, 47, 1283-1292. [CrossRef]

23. Arias, A.; Silva, C.A.; Asher, G.M.; Clare, J.C.; Wheeler, P.W. Use of a matrix converter to enhance the sensorless control of a surface-mount permanent-magnet AC motor at zero and low frequency. IEEE Trans. Ind. Electron. 2006, 53, 440-449. [CrossRef]

24. Tang, Q.; Shen, A.; Luo, X.; Xu, J. IPMSM sensorless control by injecting bi-directional rotating HF carrier signals. IEEE Trans. Power Electron. 2018, 33, 10698-10707. [CrossRef]

25. Moghadam, M.A.G.; Tahami, F. Compensation of transient error in sensorless alternating carrier injection scheme. Proc. IECON 2012, 20, 1702-1706.

26. Shen, G.; Yao, W.; Chen, B.; Wang, K.; Lee, K.; Lu, Z. Automeasurement of the inverter output voltage delay curve to compensate for inverter nonlinearity in sensorless motor drives. IEEE Trans. Power Electron. 2014, 29, 5542-5553. [CrossRef]

27. Holtz, J. Acquisition of position error and magnet polarity for sensorless control of PM synchronous machines. IEEE Trans. Ind. Appl. 2008, 44, 1172-1180. [CrossRef]

28. Xie, G.; Lu, K.Y.; Dwivedi, S.K.; Rosholm, J.R.; Blaabjerg, F. Minimum-voltage vector injection method for sensorless control of PMSM for low-speed operations. IEEE Trans. Power Electron. 2016, 31, 1785-1794. [CrossRef]

(C) 2020 by the authors. Licensee MDPI, Basel, Switzerland. This article is an open access article distributed under the terms and conditions of the Creative Commons Attribution (CC BY) license (http://creativecommons.org/licenses/by/4.0/). 